ORIGINAL ARTICLE

\title{
Breast feeding in infancy and social mobility: 60-year follow- up of the Boyd Orr cohort
}

\author{
Richard M Martin, Sarah H Goodall, David Gunnell, George Davey Smith
}

Arch Dis Child 2007;92:317-321. doi: 10.1136/adc.2006.105494

See end of article for authors' affiliations

\section{Correspondence to:}

Dr R M Martin, Department of Social Medicine, University of Bristol,

Canynge Hall, Whiteladies Road, Bristol, BS8 2PR, UK; richard.martin@bristol.ac.uk

Accepted 18December 2006
Objective: To assess the association of having been breast fed with social class mobility between childhood and adulthood.

Design: Historical cohort study with a 60-year follow-up from childhood into adulthood.

Setting: 16 urban and rural centres in England and Scotland.

Participants: 3182 original participants in the Boyd Orr Survey of Diet and Health in Pre-War Britain (193739) were sent follow-up questionnaires between 1997 and 1998. Analyses are based on 1414 (44\%) responders with data on breast feeding measured in childhood and occupational social class in both childhood and adulthood.

Main outcome: Odds of moving from a lower to a higher social class between childhood and adulthood in those who were ever breast fed versus those who were bottle fed.

Results: The prevalence of breast feeding varied by survey district (range 45-86\%) but not with household income $(p=0.7)$, expenditure on food $(p=0.3)$, number of siblings $(p=0.7)$, birth order $(p=0.5)$ or social class $(p=0.4)$ in childhood. Participants who had been breast fed were $41 \%(95 \% \mathrm{Cl} 10 \%$ to $82 \%$ ) more likely to move up a social class in adulthood $(p=0.007)$ than bottle-fed infants. Longer breastfeeding duration was associated with greater odds of upward social mobility in fully adjusted models ( $p$ for trend $=0.003$ ). Additionally controlling for survey district, household income and food expenditure in childhood, childhood height, birth order or number of siblings did not attenuate these associations. In an analysis comparing social mobility among children within families with discordant breastfeeding histories, the association was somewhat attenuated (OR 1.16; $95 \% \mathrm{Cl} 0.74$ to 1.8 ).

Conclusions: Breast feeding was associated with upward social mobility. Confounding by other measured childhood predictors of social class in adulthood did not explain this effect, but we cannot exclude the possibility of residual or unmeasured confounding.
B reast feeding in infancy may confer a number of healthrelated benefits. In the short-term, breastfed infants are at lower risk of infectious morbidity and mortality in both developing and industrialised settings. ${ }^{12}$ In the longer term, breast feeding is positively associated with height, ${ }^{34}$ may protect against several chronic diseases and their risk factors, ${ }^{5-7}$ and is related to higher $\mathrm{IQ}^{8}{ }^{89}$ improved eyesight ${ }^{10}$ and lower risk of psychiatric disorders. ${ }^{11}$

If breast feeding improves health, stature and IQ, breastfed infants might be more likely to show upward social mobility (movement up the social class hierarchy during the course of life) compared with those who were not breast fed, as better health, ${ }^{12}{ }^{13}$ greater stature ${ }^{14}$ and higher $\mathrm{IQ}^{15}{ }^{16}$ are associated with more favourable educational and occupational outcomes. We tested this hypothesis in the Boyd Orr cohort, a long-term follow-up of people born in the 1920s and 1930s in England and Scotland. ${ }^{17}$ As in other studies from this era, there was little evidence of an association between social class in childhood and breast feeding in infancy in this cohort. ${ }^{3}$ Thus, any association between breast feeding and upward social mobility is less likely to be explained by socioeconomic predictors of being breast fed that could in turn influence future social class.

\section{METHODS}

The study is an historical cohort based on the Carnegie (Boyd Orr) Survey of Diet and Health in Pre-War Britain, 1937-39. ${ }^{18}$ A total of 4999 children, aged 0-19 years, from 1343 families were surveyed at 16 centres in England and Scotland. Of the original participants, $4379(88 \%)$ have been traced and flagged using the National Health Service Central Register (NHSCR). The mean age of traced subjects at the time of the original pre-War survey was 7.1 years (SD 4.1 years; range 24 days to 19.6 years). Between 1997 and 1998, all 3182 surviving members of the Boyd Orr cohort traced at the NHSCR were sent health and lifestyle questionnaires-that is, 58-60 years after the original survey, when participants were aged between 58 and 79 years. ${ }^{19}$ After two reminders, a total of 1648 completed questionnaires were returned (52\% response).

For $1472(89 \%)$ of the questionnaire responders, a record of infant feeding method was obtained from the mother at the time of the original survey. ${ }^{18}$ We coded subjects as ever breast fed (at least 2 weeks) or exclusively bottle fed; for ever breastfed infants, we coded breastfeeding duration as: 2 weeks -2 months; $\geqslant 2-<6$ months; $\geqslant 6-<12$ months; $\geqslant 12$ months; and unknown. Social class in childhood was determined from the occupation of the male head of the household at the time of the original survey (three categories: I/ II, professional and managerial; III, skilled; IV/V, partly skilled, unskilled, other, unemployed and unclassifiable), classified according to the Registrar General's Decennial Supplement for 1931..$^{20}$ Social class in adulthood was based on the main employment of the subject (for men and unmarried women) or spouse (women), classified using the 1966 Classification of Occupations. Survey district, childhood height, number of siblings, birth order (based on the child's position among children in the household at the time of the survey ${ }^{3}$ ), per capita weekly household food expenditure and per capita weekly income in childhood (the latter two variables were coded in four categories as described previously ${ }^{3}$ ) were obtained from the original survey material. ${ }^{18}$ A total of 1414 participants $(44 \%$ 
of potentially eligible participants) had data on social class in both childhood and adulthood and on breast feeding in infancy. Ethical approval for the revitalisation of the Boyd Orr study was provided by the United Bristol's Hospital Trust Local Research Ethics Committee.

\section{ANALYSIS}

The distribution of breast feeding by categorical variables was compared using $\chi^{2}$ tests. The variable social class mobility was derived from the childhood and adulthood social class of each participant. Those whose social class stayed the same in childhood and adulthood or who moved down at least one level of social class (ie, became less advantaged) between childhood and adulthood were coded as 0 and those who moved up at least one level of social class between childhood and adulthood (ie, became more advantaged) were coded as 1 . The odds of upward social class mobility between childhood and adulthood for those who were breast fed versus those who were bottle fed was investigated by multivariable logistic regression. Robust standard errors were calculated to account for lack of independence between observations within families. We also repeated the analysis using ordinal logistic regression to test whether the results were robust to the use of a more refined measure of the outcome (coded as "moves down", "stays same" or "moves up").

The following sequentially adjusted models were developed: (1) controlling for age and sex; (2) additionally controlling for original survey district, as breast feeding was strongly geographically patterned in this cohort ${ }^{3}$ and district of origin may have influenced social mobility; (3) additionally controlling for the following variables in childhood: weekly household income and food expenditure, height and number of siblings, as these factors were associated with breast feeding in multivariable models ${ }^{3}$ and may have influenced social mobility.

We did not adjust for the participants' own educational level, as this variable may well be on the causal pathway-for example, if breast feeding improves IQ in childhood and this association in turn influences educational level and then subsequent social class. We did not have any direct measure of IQ, but we investigated whether educational level could be on the causal pathway, by (1) testing associations of breast feeding and a crude measure of education level based on the 1997-1998 questionnaire (no qualification, apprenticeship/ clerical qualification, secondary school/college, first degree and higher degree); and (2) testing whether associations of breast feeding with social mobility were attenuated after controlling for educational level.

To further investigate the potential for confounding by shared environmental exposures other than breast feeding, the association between breast feeding and social class mobility was also estimated in the subset of families who had at least one pair of children discordant for breastfeeding status (withinfamily analysis). To assess the sensitivity of our conclusions to missing data, we repeated the analyses with inverse probability weighting. ${ }^{21}$ This gives greater weight in the analysis to participants with an increased probability of missing observations and is based on developing a model predicting inclusion in the analysis. The following variables measured at baseline in childhood were included in the model predicting missing data: breastfeeding status, age at the time of the original survey, survey district, social class of the head of the household, per capita weekly family food expenditure and per capita weekly family income. Analyses were conducted using STATA V.9.

\section{RESULTS}

Response rates to the 1997-1998 survey were similar among those breast fed and bottle fed $(p=0.97)$. Those in social classes IV and lower in childhood were $54 \%$ more likely to be non-responders $(95 \%$ CI $31 \%$ to $82 \%, p<0.001)$ than social classes I-III, but there was no evidence that this socially patterned response rate differed among those who were breast fed compared with bottle fed ( $p$ for interaction $=0.15$ ). The mean age of the 1414 participants was 6.7 years (interquartile range (IQR) 3.2-9.9) at the time of the original survey, and did not differ by whether subjects were breast fed or bottle fed $(p=0.5$; table 1$)$. The prevalence of ever having been breast fed was $70 \%(n=995)$ and did not differ by sex $(p=0.5)$. Of those who were breast fed, duration of breast feeding was recorded for $682(69 \%)$, of whom $29 \%$ were breast fed for up to 6 months, $60 \%$ for $6-12$ months and $11 \%$ for $>12$ months. As reported previously for the whole cohort, the prevalence of breast feeding varied by survey district ${ }^{3}$ (range in this sample $45-86 \%$ ). There was no association between breast feeding and household income $(p=0.7)$, expenditure on food $(p=0.3)$, number of siblings $(p=0.7)$, birth order $(p=0.5)$ or social class $(p=0.4)$ in childhood (table 1$)$. Those in the highest social classes in adulthood, however, were more likely to have been breast fed during infancy than those in the lowest social classes $(\mathrm{p}=0.02)$, and $58 \%$ of those breast fed moved up a social class level versus $50 \%$ of those who were bottle fed $(p=0.004)$. Participants who were breast fed were $41 \%$ (95\% CI $10 \%$ to $82 \%$ ) more likely to move up a social class if they were breast fed during infancy than if bottle fed $(p=0.007$; table 2$)$. Additionally controlling for original survey district or for original survey district and weekly food expenditure in childhood made little difference to the age and sex adjusted OR. Among 867 participants with additional data on number of siblings, birth order, height and household income in childhood, effect estimates were similar before (OR 1.62; 95\% CI 1.2 to 2.19$)$ and after $(1.66 ; 1.22$ to 2.26$)$ also controlling for these additional factors. Results were the same if social mobility was based on a childhood social class variable that excluded those participants whose fathers were unemployed and unclassifiable $(n=929)$. Longer duration of breast feeding was associated with increased odds of upward social mobility in fully adjusted models. Although there was statistical evidence for a linear trend with ever breast fed $<6$ months as baseline ( $p=0.003$ ), the data do not suggest any additional benefit from breast feeding $>6-12$ months (table 2 ).

In a sensitivity analysis using the more refined measure of the outcome, we found that $61 \%$ of those who moved down a social class were breast fed, whereas $68 \%$ of those who stayed in the same class and $74 \%$ of those who moved up ( $p$ for heterogeneity $=0.007$ ) were breast fed. In an ordinal logistic regression model, controlling for age and sex, the OR for the association of breast feeding with social mobility measured as this 3 level outcome was 1.44 (95\% CI 1.15 to $1.8 ; p=0.001$ ), and in the fully adjusted model the OR was 1.45 (95\% CI 1.16 to $1.82 ; \mathrm{p}=0.001)$. These data indicate that the results are robust to our categorisation of the outcome.

We found some evidence that those who were breast fed were more likely to achieve at least a secondary school qualification $(27 \%)$ compared with those who were bottle fed $(20 \% ; \mathrm{p}=0.02$; table 1$)$. In a model controlling for age, sex, childhood household food expenditure and childhood social class, breastfed infants were 56\% (95\% CI 7\% to $126 \%$ ) more likely to achieve at least a secondary school qualification compared with those who were bottle fed $(\mathrm{p}=0.02$; in the basic age and sex adjusted model the OR was 1.50; 95\% CI 1.06 to 2.13). In an analysis among those with information about education level $(n=1012)$, the proportionate effect of breast feeding in relation to social mobility was attenuated by $18 \%$ (from an OR of 1.33 to 1.27 ) after additionally controlling for educational level. 
Table 1 Characteristics of the cohort

\begin{tabular}{|c|c|c|c|}
\hline & Breast fed $(n=995)$ & Bottle fed $(n=419)$ & $\mathrm{p}$ Value \\
\hline Age when assessed in childhood (mean, IQR) & $6.7(3.2$ to 10$)$ & $6.6(3.3$ to 9.2$)$ & 0.5 \\
\hline Male & $47 \%$ & $45 \%$ & 0.5 \\
\hline \multicolumn{4}{|l|}{ Social class in childhood } \\
\hline I/II & $7 \%$ & $9 \%$ & \\
\hline III & $20 \%$ & $22 \%$ & \\
\hline IV/V/other* & $72 \%$ & $69 \%$ & 0.4 \\
\hline \multicolumn{4}{|l|}{ Per capita weekly household income in childhood $†$} \\
\hline$<10 \mathrm{~s}$ & $68 \%$ & $71 \%$ & \\
\hline $10-15 \mathrm{~s}$ & $21 \%$ & $19 \%$ & \\
\hline$>15-20 \mathrm{~s}$ & $5 \%$ & $5 \%$ & \\
\hline$>20 s$ & $6 \%$ & $6 \%$ & 0.7 \\
\hline \multicolumn{4}{|c|}{ Per capita weekly household expenditure on food in childhood $\neq$} \\
\hline$<4 \mathrm{~s} 11.75 \mathrm{~d}$ & $51 \%$ & $56 \%$ & \\
\hline $5 s-6 s 11.75 d$ & $28 \%$ & $25 \%$ & \\
\hline $7 \mathrm{~s}-8 \mathrm{~s} 11.75 \mathrm{~d}$ & $13 \%$ & $11 \%$ & \\
\hline$>9 s$ & $8 \%$ & $9 \%$ & 0.3 \\
\hline Number of siblings (median, IQR) & $4(3-6)$ & $4(3-6)$ & 0.7 \\
\hline Height in childhood, SD score (mean, IQR) & $0.12(-0.52-0.69)$ & $0.02(-0.63-0.62)$ & 0.14 \\
\hline \multicolumn{4}{|l|}{ Birth order } \\
\hline 1 & $22 \%$ & $26 \%$ & \\
\hline 2 & $24 \%$ & $23 \%$ & \\
\hline 3 & $19 \%$ & $18 \%$ & \\
\hline$\geqslant 4$ & $34 \%$ & $33 \%$ & 0.5 \\
\hline \multicolumn{4}{|l|}{ Participant's own education levelt† } \\
\hline Apprenticeship/clerical qualification or less & $73 \%$ & $80 \%$ & \\
\hline Secondary school or more & $27 \%$ & $20 \%$ & 0.02 \\
\hline \multicolumn{4}{|l|}{ Social class in adulthood } \\
\hline I/II & $28 \%$ & $22 \%$ & \\
\hline III & $46 \%$ & $46 \%$ & \\
\hline IV/V/other* & $26 \%$ & $32 \%$ & 0.02 \\
\hline \multicolumn{4}{|l|}{ Social mobility between childhood and adulthood } \\
\hline Same or moved down & $42 \%$ & $50 \%$ & \\
\hline Moved up & $58 \%$ & $50 \%$ & 0.004 \\
\hline \multicolumn{4}{|c|}{ 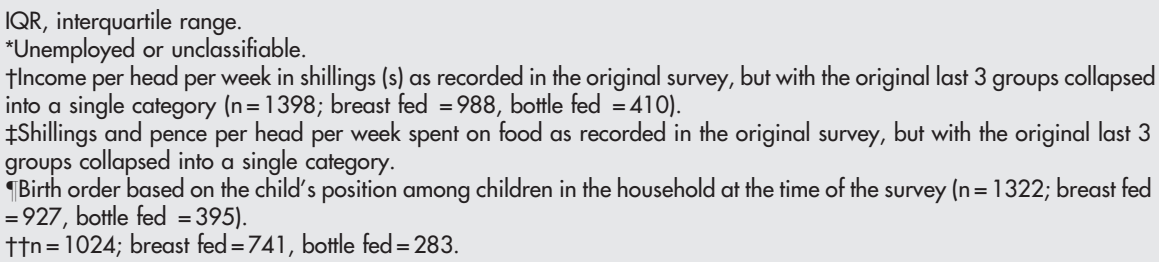 } \\
\hline
\end{tabular}

Table 2 Multivariable logistic regression analysis of social mobility in relation to ever having been breast fed and breast feeding duration in infancy $(n=1414)$

\begin{tabular}{|c|c|c|}
\hline & OR $(95 \% \mathrm{Cl})$ & p Value \\
\hline \multicolumn{3}{|l|}{ Ever breast fed vs bottle fed } \\
\hline Adjusted for age and sex & 1.41 (1.1 to 1.82$)$ & 0.007 \\
\hline Adjusted for age, sex and survey district & $1.4(1.08$ to 1.8$)$ & 0.01 \\
\hline $\begin{array}{l}\text { Adjusted for age, sex, survey district and per capita } \\
\text { weekly food expenditure in childhood }{ }^{*}\end{array}$ & 1.41 (1.09 to 1.82$)$ & 0.008 \\
\hline \multicolumn{3}{|l|}{ Duration of breast feeding vs bottle fed $\dagger$} \\
\hline Breast fed $<6$ months & $0.82(0.57$ to 1.18$)$ & - \\
\hline Breast fed 6-12 months & $1.53(1.12$ to 2.1$)$ & - \\
\hline Breast fed $>12$ months & 1.54 (0.9 to 2.63$)$ & - \\
\hline$p$ Value for trend $\neq$ & - & 0.003 \\
\hline
\end{tabular}

*Further adjustment for income group, childhood height, birth order or number of siblings in a sub-group made no material difference to the effect estimate.

†Adjusted for age, sex, survey district, per capita weekly household income and food expenditure in childhood. $\neq$ Ever breast fed for $<6$ months as baseline. 
When the analyses were reweighted to allow for missing data, the observed effect size was hardly altered (fully adjusted OR 1.37; 95\% CI 1.08 to 1.73 ). Restricting the analyses to families containing children with discordant breastfeeding history, a positive association between breast feeding and social mobility was observed in fully adjusted models, although it was attenuated with wide CIs $(\mathrm{n}=255$ families and 478 individuals; OR 1.16 ; $95 \%$ CI 0.74 to 1.8 ).

\section{DISCUSSION}

We found that ever having been breast fed was positively associated with increased odds of upward social mobility in this cohort born in the 1920s and 1930s when there was little social patterning in infancy of breast feeding. One of the most consistent findings in the published literature on the long-term impact of infant-feeding is that breast feeding is associated with improved neurocognitive development, ${ }^{8-10}$ which could influence future educational and occupational success and hence social mobility. Breast feeding was associated with education level in the Boyd Orr cohort and this variable partially attenuated the effect estimate for the breast feedingsocial mobility association. Breast feeding could perhaps also influence social class in adulthood by a direct effect on longterm health. ${ }^{5-711}$ Alternatively, an effect of breast feeding on social mobility, perhaps via improved cognition, could be a mechanism promoting long-term health, as socioeconomic circumstances over a lifetime are strongly associated with morbidity and mortality. ${ }^{22}$ Another implication of these results is that studies of the association of breast feeding with longterm health outcomes could be over-controlling for socioeconomic status if multivariable models adjust for social class in adulthood rather than in childhood.

The results should be interpreted with caution for a number of reasons. First, even though breast feeding was not as markedly socially patterned in the 1920s and 1930s as it is now, ${ }^{23-25}$ it remains possible that mothers from that era who chose to breast feed their children differed from those who did not with respect to factors associated with improved occupational prospects. The large survey-centre variations in breast feeding in the Boyd Orr cohort are in line with other studies indicating that there were marked regional influences on a mother's decision to breast feed and the duration of breast feeding in the pre-1939 era, including the working habits of mothers which varied from town to town. ${ }^{25}$ We adjusted for survey district, which may act as a proxy for regional influences affecting the decision to breast feed, but found no attenuation of effect estimates. The OR was also robust to adjustment for other factors at baseline that could be associated with adulthood social class - that is, height in childhood, number of siblings, birth order and the amount of income earned and money spent on food by their parents when the participants were children. Maternal educational level is an important potential confounding factor about which we lacked data, but we could find no empirical evidence that it was positively associated with breast feeding in the 1920s and 1930s..$^{23-25}$ The within-family analysis, however, while giving imprecise effect estimates, suggests the possibility of residual confounding because the OR was reduced from 1.41 in the full analysis to 1.16. Breast feeding may therefore be a marker for other factors that explain upward social mobility that were not fully captured by the measured covariables.

Second, although the odds of upward social mobility was highly significant ( $p=0.008$ in fully adjusted models), both the relative $(41 \%)$ and absolute $(8 \%)$ effect estimates in those breast fed versus those bottle-fed were modest. Third, reverse causality is another alternative explanation, if some of those babies who were put to the breast differed from those who were

\section{What is already known on this topic}

- Breast feeding in infancy may confer a number of benefits associated with more favourable educational and occupational outcomes, including improved health, stature and IQ.

\section{What this study adds}

- In a cohort where there was little social patterning of breast feeding in infancy, we found that breastfed infants were more likely to show upward social mobility compared with those who were bottle fed.

- Confounding by several measured childhood predictors of social class in adulthood did not explain this effect, but we cannot exclude the possibility of residual or unmeasured confounding and this finding warrants further investigation before firm conclusions are made.

not by perinatal factors associated with later socioeconomic status. For example, in the era in which this cohort was born, bottle feeding may have been limited to sicker babies already destined not to do as well in later life. We were not able to adjust for perinatal infant factors, such as early growth and health, although we have shown that birth weights were similar among breast and bottle fed infants in this cohort. ${ }^{3}$ Fourth, only $44 \%$ of 3182 potentially eligible participants were included in the analysis. Response rates to the 1997-8 survey, however, were similar by infant feeding method, and were not differential with respect to childhood social class. There was no indication of selection bias when analyses were weighted to account for missing data. Although this model assumes that the distribution of missing data can be predicted from the observed data, a strength of this database was that we were able to include several baseline sociodemographic variables in the model to estimate the probability of an observation being present. There was little attenuation of the effect estimate when this model was implemented, suggesting limited evidence of non-response bias. A strength of the study is that breastfeeding status and duration were obtained from the mother when the participants were children, avoiding recall bias.

In conclusion, breast feeding was associated with upward social mobility. Our original hypothesis was that if breast feeding really does improve health, and increase stature and IQ (as reported in many epidemiological studies $^{3-10}$ ), then breastfed infants might be more likely to show upward social mobility than those who were bottle fed. The relevance of this finding for contemporary children, therefore, is that it provides indirect support for the suggestion that having been breast fed may have long-term effects via associations with intermediate factors related to social mobility, such as growth, ${ }^{14}$ health ${ }^{12}{ }^{13}$ or IQ. ${ }^{15}{ }^{16}$ The epidemiological associations of breast feeding with these factors is inconsistent, ${ }^{26}{ }^{27}$ however, and we cannot exclude the possibility of residual or unmeasured confounding. This finding warrants further investigation, therefore, before firm conclusions are made.

\section{ACKNOWLEDGEMENTS}

RMM was funded by a Wellcome Trust research training fellowship in clinical epidemiology (GR063779FR). The funding source had no input into any aspect of the analysis, manuscript and its publication. We are grateful to the cohort members who participated in the follow-up study. We acknowledge all the research workers in the original survey in 
1937-9. We thank Professor John Pemberton for information concerning the conduct of the original survey, Professor Peter Morgan, director of the Rowett Research Institute, for the use of the archive, and Walter Duncan, honorary archivist to the Rowett, and Susie Potts for secretarial and administrative support to the study.

\section{Authors' affiliations}

Richard M Martin, David Gunnell, George Davey Smith, Department of Social Medicine, University of Bristol, Bristol, UK

Sarah H Goodall, Faculty of Medicine and Dentistry, University of Bristol, Bristol, UK

Competing interests: None.

Contributors: The hypothesis was developed by RMM. RMM undertook the analysis. SHG undertook a literature review and wrote a first draft with RMM. DG and GDS contributed intellectually to the analysis plan and to the writing of the paper. RMM coordinated completion of the paper, had full access to all the data in the study and takes responsibility for the integrity of the data and the accuracy of the analysis. All authors critically commented on earlier drafts and approved the final version of the paper.

\section{REFERENCES}

1 Kramer MS, Chalmers B, Hodnett ED, et al. Promotion of Breastfeeding Intervention Trial (PROBIT): a randomized trial in the Republic of Belarus. JAMA 2001;285:413-20.

2 Grulee CG, Sanford HN, Herron PH. Breast and artificial feeding: influence on morbidity and mortality of twenty thousand infants. JAMA 1934;103:735-9.

3 Martin RM, Davey Smith G, Mangtani P, et al. Association between breast feeding and growth: the Boyd-Orr cohort study. Arch Dis Child Fetal Neonatal Ed 2002:87:F193-201.

4 Wadsworth ME, Hardy RJ, Paul AA, et al. Leg and trunk length at 43 years in relation to childhood health, diet and family circumstances; evidence from the 1946 national birth cohort. Int J Epidemiol 2002;31:383-90.

5 Owen CG, Martin RM, Whincup PH, et al. Effect of infant feeding on the risk of obesity across the life course: a quantitative review of published evidence. Pediatrics 2005;115:1367-77

6 Martin RM, Ebrahim S, Griffin M, et al. Breastfeeding and atherosclerosis. Intima-media thickness and plaques at 65-year follow-up of the Boyd Orr Cohort. Arteriosclerosis, Thrombosis, Vascular Biol 2005;25:1482-8.

7 Martin RM, Gunnell D, Davey Smith G. Breastfeeding in infancy and blood pressure in later life: systematic review and meta-analysis. Am J Epidemiol $2005 ; 161: 15-26$

8 Anderson JW, Johnstone BM, Remley DT. Breast-feeding and cognitive development: a meta-analysis. Am J Clin Nutr 1999;70:525-35.
9 Mortensen EL, Michaelsen KF, Sanders SA, et al. The association between duration of breastffeeding and adult intelligence. JAMA 2002;287:2365-71.

10 Chong YS, Liang Y, Tan D, et al. Association between breastfeeding and likelihood of myopia in children. JAMA 2005;293:3001-2.

11 Sorensen HJ, Mortensen EL, Reinisch JM, et al. Breastfeeding and risk of schizophrenia in the Copenhagen Perinatal Cohort. Acta Psychiatr Scand 2005; 112:26-9.

12 Fox AJ, Goldblatt PO, Adelstein AM. Selection and mortality differentials. J Epidemiol Community Health 1982;36:69-79.

13 Dahl E. High mortality in lower salaried Norwegian men: the healthy worker effect? J Epidemiol Community Health 1993;47:192-4.

14 Hart CL, Davey Smith G, Blane D. Social mobility and 21 year mortality in a cohort of Scottish men. Soc Sci Med 1998;47:1121-30.

15 Neisser U, Boodoo G, Bouchard TJ, et al. Intelligence: knowns and unknowns. Am Psychol 1996:51:77-101.

16 Hart CL, Deary IJ, Taylor MD, et al. The Scottish Mental Survey 1932 linked to the Midspan studies: a prospective investigation of childhood intelligence and future health. Public Health 2003;1 17:187-95.

17 Martin RM, Gunnell D, Pemberton J, et al. The Boyd Orr cohort: an historical cohort study based on the 65 year follow-up of the Carnegie Survey of Diet and Health (1937-39). Int J Epidemiol 2005;34:742-9.

18 Rowett Research Institute. Family diet and health in pre-war Britain Dunfermline, Carnegie United Kingdom Trust, 1955.

19 Gunnell D, Berney L, Holland P, et al. How accurately are height, weight and leg length reported by the elderly and how closely are they related to measurements recorded in childhood? Int J Epidemiol 2000;29:456-64.

20 Gunnell DJ, Frankel S, Nanchahal K, et al. Lifecourse exposure and later disease: a follow-up study based on a survey of family diet and health in pre-war Britain (1937-1939). Public Health 1996;1 10:85-94

21 Ziegler A, Kastner C, Chang-Claude J. Analysis of pregnancy and other factors on detection of human papilloma virus (HPV) infection using weighted estimating equations for follow-up data. Stat Med 2003;22:2217-33.

22 Davey Smith G, Hart C, Blane D, et al. Lifetime socioeconomic position and mortality: prospective observational study. BMJ 1997;314:547-52.

23 Joint Committee of the Royal Colleges of Obstetricians and Gynaecologists and the Population Investigation Committee. Maternity in Great Britain: a survey of social and economic aspects of pregnancy and childbirth undertaken by a Join Committee of the Royal Colleges of Obstetricians and Gynaecologists and the Population Investigation Committee. London: Oxford University Press, 1948.

24 Baxter-Jones ADG, Cardy AH, Helms PJ, et al. Influence of socioeconomic conditions on growth in infancy: the 1921 Aberdeen birth cohort. Arch Dis Child 1999;81:5-9.

25 Fildes V. Infant feeding practices and infant mortality in England, 1900-1919. Continuity Change 1998;13:251-80.

26 Der G, Batty GD, Deary IJ. Effect of breast feeding on intelligence in children: prospective study, sibling pairs analysis, and meta-analysis. BMJ 2006;333:945.

27 Martin RM, Davey Smith G, Tilling K, et al. Breastfeeding and cardiovascular mortality: the Boyd Orr cohort and a systematic review with meta-analysis. Eur Heart J 2004;25:778-86. 